\title{
Effect of Bath and Luminal Potassium Concentration on Ammonia Production and Secretion by Mouse Proximal Tubules Perfused In Vitro
}

Glenn T. Nagami

With the technical assistance of Evelyn $\mathbf{M}$. Warech

Nephrology Section, Research and Medical Services, Veterans Administration Medical Center West Los Angeles, Los Angeles,

California 90073; and Department of Medicine, School of Medicine, University of California, Los Angeles, Los Angeles, California 90024

\begin{abstract}
To determine the effects of acute changes in $\mathrm{K}^{+}$concentration in vitro on ammonia production and secretion by the proximal tubule, we studied mouse $S_{2}$ segments perfused with and bathed in Krebs-Ringer bicarbonate buffers containing various $\mathrm{K}^{+}$concentrations. All bath solutions contained L-glutamine as the ammoniagenic substrate. High bath and luminal $\mathrm{K}^{+}$concentrations $(8 \mathrm{mM})$, but not high luminal $\mathrm{K}^{+}$concentration alone, inhibited total ammonia production rates by $26 \%$, while low bath and luminal $\mathrm{K}^{+}$concentrations $(2 \mathrm{mM})$, but not low luminal $\mathrm{K}^{+}$concentration alone, stimulated total ammonia production rates by $33 \%$. The stimulation of ammonia production by low bath $\mathrm{K}^{+}$concentration was not observed when $\mathrm{L}$-glutamine was added to the luminal perfusion solution. On the other hand, high luminal $\mathrm{K}^{+}$concentration stimulated, while low luminal $\mathrm{K}^{+}$concentration inhibited, net luminal secretion of total ammonia in a way that was: $(a)$ independent of total ammonia production rates, (b) independent of $\mathrm{Na}^{+}-\mathrm{H}^{+}$exchange activity, and $(c)$ not due to changes in transepithelial fluxes of total ammonia. These results suggest that luminal potassium concentration has a direct effect on cell-to-lumen transport of ammonia. (J. Clin. Invest. 1990. 86:32-39.) Key words: ammoniagenesis • ammonia transport • L-glutamine transport
\end{abstract}

\section{Introduction}

Renal ammonia production and excretion are intimately related to potassium homeostasis (1). Hypokalemia associated with potassium depletion in vivo enhances ammonia excretion and production by the kidney (2-4), while hyperkalemia with potassium loading in vivo diminishes ammonia excretion (5). In contrast, studies of the direct effects of altered extracellular potassium concentration in vitro on ammonia production by renal tissue have not been as definitive. Increasing the potassium concentration beyond the physiological range suppressed rates of ammonia production by rat cortical slices (6) and cortical tubule and isolated perfused kidney preparations (7). Decreasing the bath concentration of potassium by nominal removal of potassium in vitro stimulated ammonia production by $10 \%(6)$, while no significant response to low potassium was observed in cortical tubule fragments or isolated perfused kidneys (7). One reason for the discrepancy between in vivo

Address correspondence to Dr. Glenn T. Nagami, Nephrology Section 691//W111L, Veterans Administration Medical Center West Los Angeles, Wilshire and Sawtelle Blvds., Los Angeles, CA 90073.

Received for publication 1 August 1988 and in revised form 27 February 1990.

The Journal of Clinical Investigation, Inc.

Volume 86, July 1990, 32-39 and in vitro results could have been the differences in time of exposure to abnormal potassium concentrations in the in vivo and in vitro models. Another possibility was that the in vitro and in vivo models differed in other fundamental ways. For example, under in vivo conditions the fluid within the tubular lumen constantly flows by the apical aspect of the proximal tubule cells, whereas in tissue slice and cortical tubular preparations the lumen may be open but the flow past the luminal aspect of the tubule may be quite limited because of the lack of a pressure gradient. Because the proximal tubule perfused in vitro would more closely approximate in vivo conditions, and because we have demonstrated the quantitatively important effect of luminal perfusion on total ammonia $\left(\mathrm{NH}_{3}+\mathrm{NH}_{4}^{+}\right)$ production $(8,9)$, we examined the effects of altered ambient potassium concentration in vitro on total ammonia production rates in mouse proximal tubules perfused in vitro.

In previous studies we examined the effects of luminal perfusion and metabolic acidosis on total ammonia production rates and net luminal secretion of the total ammonia by the mouse proximal tubule perfused in vitro $(8,9)$. The advantages of this approach are that a specific segment of the nephron may be dissected, that the lumen of the dissected segment is perfused resulting in more physiologic conditions than unperfused nephron segments, that total ammonia production rates and net luminal secretion of total ammonia may be measured in the specific segments of the nephron, and that bath and luminal conditions may be controlled. In these studies we examined the effects of altered bath and luminal potassium concentrations on total ammonia production and net total ammonia secretion in mouse proximal tubule segments perfused in vitro. These studies demonstrate the important effects of bath and luminal potassium concentrations, but not luminal potassium concentration alone, on total ammonia production rates, and the influence of luminal potassium concentration on net luminal secretion of total ammonia.

\section{Methods}

Animals. Male Swiss Webster mice weighing 25-35 g consumed rodent chow (Ralston Purina Co., St. Louis, MO) and water ad lib as in our previous studies (8-10).

Isolation and perfusion of mouse proximal tubules. The methods used for isolating, perfusing, and incubating mouse proximal tubules were described in greater detail in our previous papers (8-10). Briefly, mouse proximal tubules consisting of the late convoluted and early straight portions (" $S_{2}$ ") were dissected. The length of each segment varied from 0.6 to $1.1 \mathrm{~mm}$ but there were no significant differences in mean tubule length among the groups compared. Each segment was placed in a modified perfusion chamber in which the volume was reduced to $\sim 200 \mu$ l. In studies examining total ammonia production, one end of the tubule was cannulated and perfused with KRB buffer (see below), while the distal end remained open to the bath medium. All tubules were bathed at $37^{\circ} \mathrm{C}$ in $\mathrm{KRB}$ buffer containing $0.5 \mathrm{mM}$ 
L-glutamine and $1.0 \mathrm{mM}$ acetate, equilibrated with $95 \% \mathrm{O}_{2}: 5 \% \mathrm{CO}_{2}$, pH 7.4. The bath solution was covered with mineral oil pregassed with $95 \% \mathrm{O}_{2}: 5 \% \mathrm{CO}_{2}$. A gas jet bubbled the mineral oil directly above the tubule so that the tubule was agitated in the bath medium. At the end of the 30-min incubation period an aliquot of bath medium was assayed for total ammonia using the bacterial luciferase bioluminescence assay that we developed previously (8). The actual volume of the bath solution at the end of the incubation period was calculated from the dilution of known amounts of trypan blue dye. It should be noted that in preliminary studies in which new incubation conditions were examined, aliquots of bath medium were sampled at 15-min intervals to confirm the constancy of the rate of ammonia production during a chosen incubation period. As in previous studies, we also noted that the addition of acetate to the incubation medium had no significant effect on the rates of total ammonia production, but appeared to stabilize total ammonia production rates at a constant level for longer periods. More detailed descriptions of the experimental conditions in which bath and/or luminal potassium concentrations were altered are presented in Results. The data presented in each of the figures represent data obtained in separate tubule segments in which control studies were randomly interposed among experimental studies.

In studies in which net luminal secretion was measured, the fluid leaving the distal end of the perfused segment was collected with a second pipette (10). The ammonia content in timed luminal fluid collections was measured and net luminal secretion calculated as described previously.

Measurement of total ammonia. The total ammonia $\left(\mathrm{NH}_{3}+\mathrm{NH}_{4}^{+}\right)$ assay was the same assay used in our previous studies (8). It was based on the coupling of the glutamic dehydrogenase, glucose-6-phosphate dehydrogenase, and NAD:FMN oxidoreductase reactions to the bacterial luciferase bioluminescence reaction. Light was the end-product of these reactions and was measured by a photometer (model 20; Turner Designs, Mountain View, CA).

Measurement of luminal fluid potassium concentration and $\mathrm{pH}$. Luminal fluid potassium concentration was measured using ion-selective liquid ion-exchanger electrodes. $\mathrm{K}$-sensitive electrodes were produced from $1 \mathrm{~mm}$ borosilicate glass tubing, which was pulled by a micropipette puller (model 750; David Kopf Instruments, Tujunga, CA). The tip was broken to a diameter of $<10 \mu$. The tip was silanized by adding $2 \%$ tri- $N$-butylchlorosilane in carbon tetrachloride to the tip and then heating the pipette on a hotplate (Corning Glass Works, Corning, NY) for 5 min. K-sensitive liquid ion exchanger (World Precision Instruments, New Haven, CT) was added by front-filling, and $0.5 \mathrm{M} \mathrm{KCl}$ was added as a back-fill solution. A small portion of the tip was desilanized by drawing $5 \mathrm{M} \mathrm{KOH}$ into the tip as previously described by us (10). The pipette was connected to a high input impedance electrometer (FD 223; World Precision Instruments) using Ag:AgCl wires. The $\mathrm{K}$-sensitive electrode demonstrated a slope of 54 $\mathrm{mV} /$ decade $\Delta[\mathrm{K}]$. The pH-sensitive electrode was constructed in the same fashion except that a pH-sensitive liquid ion exchanger was used as described previously (10).

To measure the luminal fluid potassium concentration and $\mathrm{pH}$, the ion-sensitive pipette was passed down the barrel of the collection microperfusion pipette holding the distal end of the perfused segment within a pipette containing GE silicone fluid to form an electrical seal. To enhance the reliability of measurements, the tip of the K-sensitive pipette was placed within the narrow portion of the collection pipette holding the perfused segment and was positioned immediately at the opening of the perfused tubule so that the tip of the pipette was exposed to the fluid leaving the distal end of the perfused segment. Because the shank of the K-sensitive pipette was narrower and longer than the narrowest section of the holding pipette, the flow of luminal fluid was not impeded. A second reference pipette was subsequently introduced into the luminal fluid to determine the transepithelial voltage. The readings of each pipette electrode were compared with a reference electrode placed in the bath solution.

L-Glutamine reabsorption. Uniformly labeled $\left[{ }^{14} \mathrm{C}\right] \mathrm{L}$-glutamine (Amersham Corp., Arlington Heights, IL) was added to the luminal perfusion solution containing $0.5 \mathrm{mM}$ L-glutamine final concentration. The luminal fluid leaving the distal end of the perfused segment was collected and fractionated on two ion exchange columns consisting of Dowex-1 and Amberlite as described, which permitted separation of L-glutamine from glutamate and from dicarboxylate compounds (11). Greater than $94 \%$ of the label leaving the distal end of the perfused segment eluted with L-glutamine. The rate at which L-glutamine was delivered to the proximal end of the perfused segment (flow $X$ concentration) was subtracted from the rate at which L-glutamine left the distal end of the perfused segment to obtain the unidirectional L-glutamine reabsorption rate.

Calculations. Total ammonia production rates were determined in proximal tubule segments in which the distal end of the perfused segment remained open to the bath medium so that the total ammonia was released by the tubule segment into the bath medium via the luminal and peritubular aspects of the perfused tubule segment. The rate of total ammonia production thus equaled the rate of accumulation of total ammonia in the bath medium under these conditions. Net luminal secretion of total ammonia was calculated from the measurement of the total ammonia contained in timed luminal fluid collections made with a second collection pipette. Luminal flow rate was determined by the addition of known amounts of exhaustively dialyzed $\left[{ }^{3} \mathrm{H}\right]$ methoxyinulin to the perfusion solution.

The apparent total ammonia permeability, $P_{\text {ammonia }}$, was calculated from the total ammonia flux rate divided by the product of the surface area and the mean total ammonia concentration gradient. The results were presented in units of centimeters per second.

Statistical comparisons among three or more groups were made using the method of Scheffe for the analysis of variance with multiple comparisons (12) and comparisons between two groups were made using the $t$ test. All data are presented as mean \pm SE.

Solutions. The standard or control buffer was a modified KRB buffer containing $124 \mathrm{mM} \mathrm{NaCl}, 25 \mathrm{mM} \mathrm{NaHCO}_{3}, 5 \mathrm{mM} \mathrm{KCl}, 1 \mathrm{mM}$ $\mathrm{MgCl}_{2}, 1 \mathrm{mM} \mathrm{NaH}_{2} \mathrm{PO}_{4}$, and $1 \mathrm{mM} \mathrm{CaCl}_{2}$. In experiments in which the potassium concentration was altered, the sodium concentration was altered by the same amount in the opposite direction while maintaining a constant chloride concentration. In studies examining the effects of the inhibition of $\mathrm{Na}^{+}-\mathrm{H}^{+}$exchanger, the tubule segments were perfused with a modified $10 \mathrm{mM}$ sodium KRB buffer containing $0.1 \mathrm{mM}$ amiloride, in which sodium chloride was isoosmotically substituted with mannitol and the potassium concentration was adjusted by altering the potassium bicarbonate concentration while changing the choline bicarbonate concentration in the opposite direction. Perfusion with such a modified perfusate inhibited net fluid reabsorption and measurable luminal acidification $(8,10)$.

\section{Results}

Under each of the experimental conditions studied, total ammonia production rates were constant for at least $45 \mathrm{~min}$ of incubation at $37^{\circ} \mathrm{C}$. All incubations were completed in $<45$ min. In addition, all tubules excluded trypan blue dye added at the end of each experimental incubation period. The tubule segment lengths and luminal flow rates observed in each of the groups of tubules studied were not significantly different from each other with an overall mean flow rate of $21.0 \pm 0.8 \mathrm{nl} / \mathrm{min}$.

Total ammonia production rates were measured in proximal tubules bathed and perfused with various KRB buffers containing 2, 5 (control), or $8 \mathrm{mM}$ potassium (Fig. 1). Proximal tubule segments bathed in $5 \mathrm{mM} \mathrm{K}^{+} \mathrm{KRB}$ buffer containing $0.5 \mathrm{mM}$ L-glutamine and perfused with $5 \mathrm{mM} \mathrm{K}^{+} \mathrm{KRB}$ buffer produced total ammonia at a rate of $20.7 \pm 0.9 \mathrm{pmol} /$ min per $\mathrm{mm}$, which was significantly higher than proximal tubule segments perfused with and bathed in $8 \mathrm{mM} \mathrm{KRB}$ buffer, $15.3 \pm 1.3 \mathrm{pmol} / \mathrm{min}$ per $\mathrm{mm}(P<0.02)$, and significantly lower than tubules perfused with and bathed in $2 \mathrm{mM}$ 


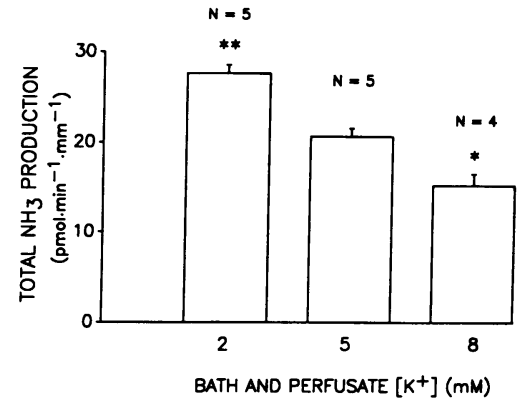

KRB buffer, $27.6 \pm 0.9 \mathrm{pmol} / \mathrm{min}$ per $\mathrm{mm}(P<0.01)$. Thus, ammonia production was $26 \%$ lower in tubules bathed in 8 $\mathrm{mM} \mathrm{K}^{+} \mathrm{KRB}$ buffer and 33\% higher in tubules bathed in 2 $\mathrm{mM} \mathrm{K}^{+}$buffer than in tubules bathed in and perfused with the control $5 \mathrm{mM} \mathrm{K}^{+} \mathrm{KRB}$ buffer.

One of the advantages of the in vitro microperfusion system is that luminal conditions may be altered while maintaining constant peritubular (bath) conditions. To examine the effect of altering the luminal potassium concentration on total ammonia production rates, total ammonia production rates were measured in tubules perfused with KRB buffer containing 0,5 , or $10 \mathrm{mM}$ potassium, but bathed with $5 \mathrm{mM} \mathrm{K}^{+} \mathrm{KRB}$ buffer containing $0.5 \mathrm{mM}$ L-glutamine (Fig. 2). To confirm that the intraluminal potassium concentration was altered, we measured the potassium concentration in fluid leaving the distal end of the perfused segment. Table I summarizes the data observed in tubules perfused with $\mathrm{KRB}$ buffer containing either 0,5 , or $10 \mathrm{mM}$ potassium while maintaining a constant bath potassium concentration of $5 \mathrm{mM}$. We also measured luminal fluid $\mathrm{pH}$ to determine whether luminal potassium concentration affected luminal pH (Table I). Luminal pH was not affected by perfusion with the various KRB buffers containing 0,5 , or $10 \mathrm{mM}$ potassium. Perfusion with 0 or $10 \mathrm{mM}$ potassium KRB buffer did, in fact, alter the collected fluid potassium concentration compared with tubules perfused with the $5 \mathrm{mM}$ potassium KRB buffer. Measurement of total ammonia production rates in tubules perfused with the various KRB buffers containing different potassium concentrations while maintaining a constant bath potassium concentration had no significant effect on total ammonia production rates (Fig. 2). The total ammonia production rate was $20.5 \pm 0.9$ $\mathrm{pmol} / \mathrm{min}$ per $\mathrm{mm}$ in tubules perfused with the $5 \mathrm{mM}$ potassium buffer, $20.6 \pm 0.9 \mathrm{pmol} / \mathrm{min}$ per $\mathrm{mm}$ in tubules perfused with $10 \mathrm{mM}$ potassium buffer, and $20.4 \pm 0.9 \mathrm{pmol} / \mathrm{min}$ per $\mathrm{mm}$ in tubules perfused with $0 \mathrm{mM}$ potassium buffer. Thus, total ammonia production rates are affected by changes in

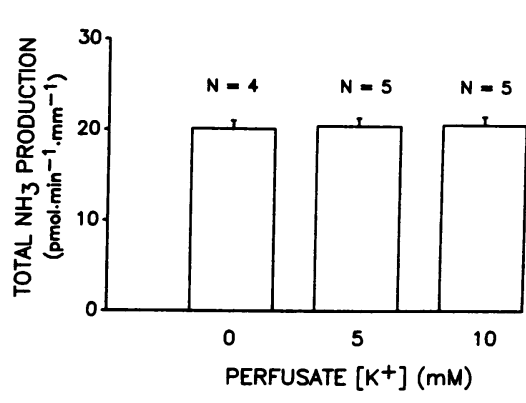

Figure 2. Total ammonia production rates by proximal tubule segments perfused with KRB buffer containing 0,5 , or $10 \mathrm{mM}$ potassium. All tubules were bathed in KRB buffer containing $5 \mathrm{mM}$ potassium. There were no significant differences among groups.
Table I. Effect of Perfusate Potassium Concentration on Collected Luminal Fluid Potassium Concentration and pH

\begin{tabular}{|c|c|c|c|c|}
\hline $\begin{array}{c}\text { Perfusate } \\
{\left[\mathbf{K}^{+}\right]}\end{array}$ & $n$ & Flow rate & $\begin{array}{l}\text { Collected } \\
\text { fluid }\left[\mathrm{K}^{+}\right]\end{array}$ & $\begin{array}{l}\text { Collected } \\
\text { fluid pH }\end{array}$ \\
\hline$m M$ & & $\mathrm{nl} / \mathrm{min}$ & $m M$ & \\
\hline 0 & 5 & $21.0 \pm 0.4$ & $2.4 \pm 0.2^{*}$ & $7.39 \pm 0.02$ \\
\hline 5 & 5 & $21.3 \pm 0.4$ & $5.2 \pm 0.2$ & $7.37 \pm 0.01$ \\
\hline 10 & 5 & $21.3 \pm 0.5$ & $7.7 \pm 0.2^{*}$ & $7.37 \pm 0.01$ \\
\hline
\end{tabular}

* $P<0.01$ vs. $5 \mathrm{mM}$ potassium perfusate group. All tubules were bathed in KRB buffer, pH 7.44, containing $5 \mathrm{mM}$ potassium.

peritubular and luminal potassium concentration but not by changes in luminal potassium concentration alone.

The stimulatory effect of low bath and perfusate potassium concentrations on total ammonia production was relatively large when compared with previous studies by others. One possible explanation for the differences in results may be related to differences in the availability of luminal substrate observed in our preparation and the preparations used by others. In the present study, mouse proximal tubule segments were bathed in buffer containing L-glutamine, while the apical aspect was perfused with glutamine-free buffer. On the other hand, in cortical tubule and isolated perfused whole kidney preparations, substrates may have access to the proximal tubule cell via peritubular and luminal aspects. We re-examined the effect of bath and perfusate potassium concentrations in tubules perfused with KRB buffer containing L-glutamine (Fig. 3). Proximal tubule segments were bathed and perfused with 2,5 , or $8 \mathrm{mM}$ potassium concentration in which $0.5 \mathrm{mM}$ L-glutamine was also added to the perfusate. All experiments were performed with $0.5 \mathrm{mM} \mathrm{L}$-glutamine in the bath solution. A group of proximal tubule segments was also bathed in $2 \mathrm{mM}$ $\mathrm{K}^{+} \mathrm{KRB}$ buffer containing L-glutamine and perfused with 2 mM K ${ }^{+}$KRB buffer without L-glutamine. Total ammonia production rates were not significantly different among tubules bathed in and perfused with $2 \mathrm{mM} \mathrm{K}^{+} \mathrm{KRB}$ buffer with and without L-glutamine in the perfusate $(28 \pm 2 \pm 1.0$ and $29.4 \pm 1.5 \mathrm{pmol} / \mathrm{min}$ per $\mathrm{mm}$ ) and tubules bathed in and perfused with $5 \mathrm{mM} \mathrm{KRB}$ buffer with L-glutamine in the perfusate $(29.4 \pm 1.2 \mathrm{pmol} / \mathrm{min}$ per $\mathrm{mm})$. The total ammonia production rate observed in proximal tubule segments bathed in and perfused with $8 \mathrm{mM} \mathrm{K}^{+} \mathrm{KRB}$ buffer with $0.5 \mathrm{mM} \mathrm{L-glutamine}$ was lower than the rate observed in tubules bathed in and perfused with $5 \mathrm{mM} \mathrm{K}^{+} \mathrm{KRB}$ buffer with L-glutamine in the perfusate $(23.0 \pm 0.9$ vs. $29.4 \pm 1.2 \mathrm{pmol} / \mathrm{min}$ per $\mathrm{mm}, P$ $<0.05)$. The total ammonia production rate observed in proximal tubule segments bathed in and perfused with $5 \mathrm{mM}$

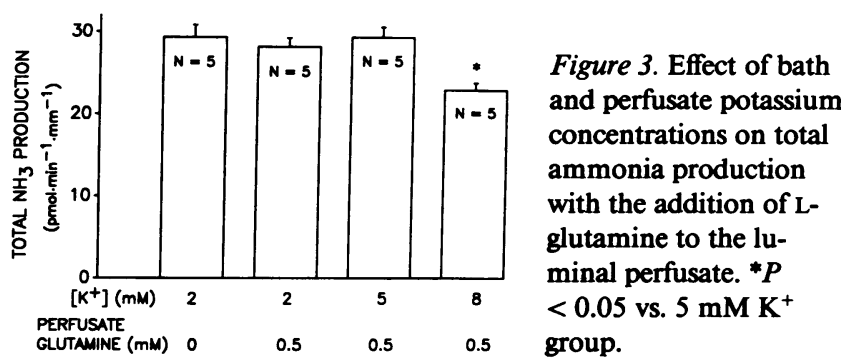


$\mathrm{K}^{+} \mathrm{KRB}$ buffer in which L-glutamine was added to the perfusate increased to the level observed in tubules bathed in and perfused with $2 \mathrm{mM} \mathrm{K}^{+} \mathrm{KRB}$ buffer with or without L-glutamine in the perfusate. Thus the exposure of both luminal and basolateral aspects of the proximal tubule to L-glutamine eliminated the stimulation of total ammonia production observed with low bath and luminal potassium concentrations, while it did not eliminate the inhibition of total ammonia production by high ambient potassium concentration.

The presence of luminal L-glutamine could have enhanced substrate delivery and ammonia production under control and low bath potassium conditions. This enhanced delivery of $L-$ glutamine might have maximized ammonia production rates so that the effects of low bath potassium might have been overshadowed. We examined the luminal absorption of $\left[{ }^{14} \mathrm{C}\right] \mathrm{L}$-glutamine in five proximal tubule segments bathed in 5 and 2-mM bath potassium concentrations. The L-glutamine concentration in the luminal perfusion solution was $0.5 \mathrm{mM}$. L-Glutamine reabsorption occurred at a rate of $6.8 \pm 0.5 \mathrm{pmol} /$ min per $\mathrm{mm}$ in tubules bathed in and perfused with $5 \mathrm{mM} \mathrm{K}^{+}$ KRB buffer and did not significantly change when the tubules were bathed in and perfused with $2 \mathrm{mM} \mathrm{K}{ }^{+} \mathrm{KRB}$ buffer $(7.3 \pm 0.7 \mathrm{pmol} / \mathrm{min}$ per $\mathrm{mm})$. These results indicate that Lglutamine reabsorption occurs at a high rate, and that altered bath potassium concentration has no affect on unidirectional L-glutamine reabsorption.

In addition to measuring total ammonia production rates with different bath and perfusion potassium concentrations, we also measured net luminal total ammonia secretion rates by collecting the fluid leaving the distal end of perfused proximal tubule segments. Net total ammonia secretion rates were first measured in tubules bathed in and perfused with KRB buffers containing 2,5 , or $8 \mathrm{mM}$ potassium (Fig. 4). All bath solutions but none of the perfusate solutions contained 0.5 mM L-glutamine. The net luminal total ammonia secretion rate was $11.0 \pm 0.4 \mathrm{pmol} / \mathrm{min}$ per $\mathrm{mm}$ in tubules perfused with and bathed in $5 \mathrm{mM} \mathrm{K} \mathrm{K}^{+} \mathrm{KRB}$ buffer, which was significantly higher than the rate observed in tubules perfused with and bathed in $2 \mathrm{mM} \mathrm{K}{ }^{+} \mathrm{KRB}$ buffer, $7.2 \pm 0.5 \mathrm{pmol} / \mathrm{min}$ per $\mathrm{mm}$ $(P<0.01)$, but was not significantly different from tubules bathed in and perfused with $8 \mathrm{mM} \mathrm{K}^{+} \mathrm{KRB}$ buffer, $10.8 \pm 0.4$ $\mathrm{pmol} / \mathrm{min}$ per $\mathrm{mm}$. These results were remarkable in that, as in Fig. 1, total ammonia production rates were higher in tubules bathed and perfused in $2 \mathrm{mM} \mathrm{K}{ }^{+} \mathrm{KRB}$ buffer and lower in tubules bathed in and perfused with $8 \mathrm{mM} \mathrm{K}^{+} \mathrm{KRB}$ buffer than in tubules bathed in and perfused with $5 \mathrm{mM} \mathrm{K}^{+} \mathrm{KRB}$ buffer.

To examine the role of altered luminal potassium concentration alone on net total ammonia secretion rates, we measured net total ammonia secretion rates in tubules bathed in 5 $\mathrm{mM} \mathrm{K}^{+} \mathrm{KRB}$ buffer containing $0.5 \mathrm{mM}$ L-glutamine and per-

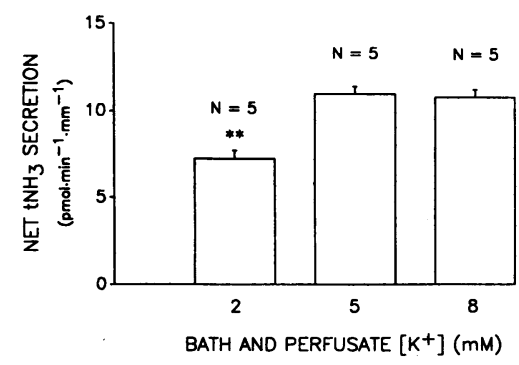

Figure 4. Rates of net total ammonia secretion in proximal tubules bathed and perfused in KRB buffer containing 2,5 , or $8 \mathrm{mM}$ potassium. ${ }^{* *} P<0.01$ vs. the other two groups.

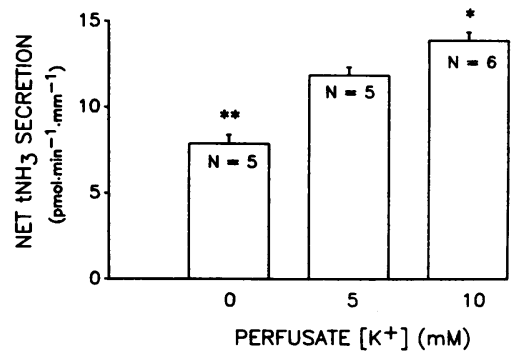

Figure 5. Rates of net total ammonia secretion in proximal tubules perfused with KRB buffer containing 0,5 , or $10 \mathrm{mM}$ potassium. All tubules were bathed in KRB buffer containing $5 \mathrm{mM}$ potassium. ${ }^{*} P<0.05$ vs. $5 \mathrm{mM} \mathrm{K}^{+}$ group; ${ }^{* *} P<0.01$ vs. the other two groups.

fused with either 0,5 , or $10 \mathrm{mM} \mathrm{K} \mathrm{K}^{+} \mathrm{KRB}$ buffer without L-glutamine (Fig. 5). The net total ammonia secretion rate was $7.9 \pm 0.5 \mathrm{pmol} / \mathrm{min}$ per $\mathrm{mm}$ in tubules perfused with $0 \mathrm{~K}^{+}$ $\mathrm{KRB}$ buffer, $11.9 \pm 0.5$ in tubules perfused with $5 \mathrm{~K}^{+} \mathrm{KRB}$ buffer, and $13.9 \pm 0.5 \mathrm{pmol} / \mathrm{min}$ per $\mathrm{mm}$ in tubules perfused with $10 \mathrm{mM} \mathrm{K}^{+} \mathrm{KRB}$ buffer. The values for net total ammonia secretion rates were significantly different among the various groups, such that the mean of the group of proximal tubules perfused with the $0 \mathrm{~K}^{+} \mathrm{KRB}$ buffer was significantly lower than the means of the other two groups $(P<0.01)$, and the mean group perfused with the $10 \mathrm{mM} \mathrm{K} \mathrm{K}^{+} \mathrm{KRB}$ buffer was significantly higher than the group perfused with $5 \mathrm{mM} \mathrm{K}^{+}$ KRB buffer $(P<0.05)$. Thus, even though changing the luminal potassium concentration had no effect on total ammonia production rates (Fig. 2), a higher luminal potassium concentration was associated with a higher rate of net luminal ammonia secretion, while a lower luminal potassium concentration was associated with a lower rate of net ammonia secretion.

In our previous studies we demonstrated the important role of $\mathrm{Na}^{+}-\mathrm{H}^{+}$exchange in the mechanism of net luminal total ammonia secretion in mouse proximal tubule segments (10). We assessed the role of $\mathrm{Na}^{+}-\mathrm{H}^{+}$exchange in net luminal total ammonia secretion by perfusing mouse proximal tubule segments with a modified KRB buffer containing $0.1 \mathrm{mM}$ amiloride and $10 \mathrm{mM}$ sodium. We previously demonstrated that perfusion of mouse proximal tubule segments with this solution inhibited net fluid reabsorption and inhibited measurable luminal acidification (10).

In this study, the $\mathrm{K}^{+}$concentration of the modified $\mathrm{KRB}$ perfusate containing amiloride was set at 5 or $10 \mathrm{mM}$ to determine the effect of the inhibition of $\mathrm{Na}^{+}-\mathrm{H}^{+}$exchange on the enhanced rate of net luminal total ammonia secretion observed with increased luminal $\mathrm{K}^{+}$concentration (Fig. 6). All tubules were bathed in $5 \mathrm{mM} \mathrm{K}^{+} \mathrm{KRB}$ buffer containing 0.5 mM L-glutamine. Perfusion with the modified KRB buffers

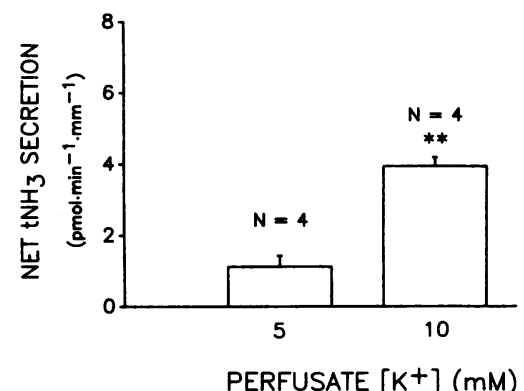

Figure 6. Rates of net total ammonia secretion in proximal tubule segments perfused with modified KRB buffer containing $0.1 \mathrm{mM}$ amiloride and 5 or 10 $\mathrm{mM}$ potassium. All tubules were bathed in KRB buffer containing $5 \mathrm{mM}$ potassium. ${ }^{*} P$ $<0.01$. 
containing amiloride inhibited measurable luminal fluid acidification such that the collected fluid $\mathrm{pH}$ was $7.36 \pm 0.01$ in five tubules perfused with the control KRB buffer (initial $\mathrm{pH}$, $7.43 \pm 0.01$ ) and was $7.44 \pm 0.01$ or $7.43 \pm 0.01$ in five tubules perfused with the modified $\mathrm{KRB}$ buffer containing $5 \mathrm{mM} \mathrm{K}^{+}$ (initial pH, 7.43 \pm 0.01 ) or $10 \mathrm{mM} \mathrm{K}^{+}$(initial pH, 7.44 \pm 0.01 ). As was demonstrated previously $(8,10)$, perfusion with the modified KRB buffer had no significant effect on total ammonia production rates. The total ammonia production rate in tubules perfused with the modified $5 \mathrm{mM} \mathrm{K} \mathrm{K}^{+} \mathrm{KRB}$ buffer containing amiloride was $20.8 \pm 0.9 \mathrm{pmol} / \mathrm{min}$ per $\mathrm{mm}(n=4)$, which was not significantly different from tubules perfused with the modified $10 \mathrm{mM} \mathrm{K} \mathrm{KRB}^{+} \mathrm{KRuffer}$ containing amiloride, $21.2 \pm 1.0 \mathrm{pmol} / \mathrm{min}$ per $\mathrm{mm}(n=4)$. On the other hand, net luminal total ammonia secretion rates were significantly higher in tubules perfused with the $10 \mathrm{mM} \mathrm{K}^{+}$modified $\mathrm{KRB}$ buffer containing amiloride, $4.0 \pm 0.2 \mathrm{pmol} / \mathrm{min}$ per $\mathrm{mm}$, than in tubules perfused with the $5 \mathrm{mM} \mathrm{K}^{+}$modified $\mathrm{KRB}$ buffer containing amiloride, $1.4 \pm 0.2 \mathrm{pmol} / \mathrm{min}$ per $\mathrm{mm}(P<0.01)$. Thus, a higher rate of net total ammonia secretion was observed in tubules perfused with the $10 \mathrm{mM} \mathrm{K}^{+}$modified KRB buffer than in tubules perfused with $5 \mathrm{mM} \mathrm{K}^{+}$modified $\mathrm{KRB}$ buffer. The absolute difference in the rates of net total ammonia secretion in the tubules perfused with the $5 \mathrm{mM} \mathrm{K}^{+}$versus the $10 \mathrm{mM} \mathrm{K}^{+}$modified $\mathrm{KRB}$ buffer was $2.6 \mathrm{pmol} / \mathrm{min}$ per $\mathrm{mm}$, which was similar to the difference in the rates of net total ammonia secretion observed between tubules perfused with the $5 \mathrm{mM}$ versus $10 \mathrm{mM} \mathrm{K}^{+} \mathrm{KRB}$ buffer containing normal amounts of sodium and no amiloride $(2.0 \mathrm{pmol} / \mathrm{min}$ per $\mathrm{mm})$.

Because changes in the rate of net secretion of ammonia could reflect changes in the rate of secretion of ammonia from cell to lumen or changes in efflux out of the luminal fluid, we examined the effect of altered luminal $\mathrm{K}^{+}$concentration on the rate of efflux of total ammonia out of the luminal fluid (Table II). In these studies, the luminal perfusion solution contained $10 \mathrm{mM}$ total ammonia and various concentrations of $\mathrm{K}^{+}(0,5$, or $10 \mathrm{mM})$. The luminal fluid leaving the distal end of the perfused segment was collected and measured for total ammonia. The rate of total ammonia leaving the distal end of the perfused segment represented the total ammonia not reabsorbed by the perfused segment so that the difference between the rate at which total ammonia left the distal end of the perfused segment and the rate delivered at the beginning of the segment represented the efflux of total ammonia. As shown in Table II, neither the rates of total ammonia efflux nor the calculated apparent total ammonia permeabilities significantly differed among groups of proximal tubules perfused with 0,5 , or $10 \mathrm{mM} \mathrm{K}^{+}$solutions. The results of these studies indicate

Table II. Total $\mathrm{NH}_{3}$ Efflux Rates

\begin{tabular}{|c|c|c|c|c|c|c|}
\hline $\begin{array}{l}\text { Perfusate } \\
{\left[\mathbf{K}^{+}\right]}\end{array}$ & $n$ & $\begin{array}{l}\text { Tubule } \\
\text { length }\end{array}$ & Flow rate & $\begin{array}{c}\text { Collected } \\
\text { fluid } \\
{\left[\mathrm{tNH}_{3}\right]}\end{array}$ & Exit rate & $\begin{array}{c}\text { Total } \mathrm{NH}_{3} \\
\text { permeability } \\
\times 10^{-4}\end{array}$ \\
\hline$m M$ & & $\mathrm{~mm}$ & $n l / m i n$ & $m M$ & $\begin{array}{c}\mathrm{pmol} / \mathrm{min} \\
\mathrm{per} \mathrm{mm}\end{array}$ & $\mathrm{cm} / \mathrm{s}$ \\
\hline 0 & 14 & $0.8 \pm 0.1$ & $22.1 \pm 0.9$ & $1.9 \pm 0.2$ & $221 \pm 16$ & $6.6 \pm 0.6$ \\
\hline 5 & 12 & $0.9 \pm 0.1$ & $21.3 \pm 1.0$ & $1.7 \pm 0.1$ & $207 \pm 14$ & $6.3 \pm 0.6$ \\
\hline 10 & 12 & $0.9 \pm 0.1$ & $21.9 \pm 0.8$ & $1.6 \pm 0.2$ & $204 \pm 10$ & $6.2 \pm 0.5$ \\
\hline
\end{tabular}

All perfusates initially contained $10 \mathrm{mM}$ total ammonia $\left(\mathrm{tNH}_{3}\right)$.
Table III. Total $\mathrm{NH}_{3}$ Entry Rates

\begin{tabular}{|c|c|c|c|c|c|c|}
\hline $\begin{array}{l}\text { Bath } \\
{\left[\mathbf{K}^{+}\right]}\end{array}$ & $n$ & Tubule length & Flow rate & $\begin{array}{c}\text { Collected } \\
\text { fluid } \\
{\left[\mathrm{tNH}_{3}\right]}\end{array}$ & $\begin{array}{l}\text { Total } \mathrm{NH}_{3} \\
\text { entry rate }\end{array}$ & $\begin{array}{l}\text { Total } \mathrm{NH}_{3} \\
\text { permeability } \\
\times 10^{-4}\end{array}$ \\
\hline$m M$ & & $m m$ & $\mathrm{nl} / \mathrm{min}$ & $m M$ & $\begin{array}{c}\mathrm{pmol} / \mathrm{min} \\
\mathrm{per} \mathrm{mm}\end{array}$ & $\mathrm{cm} / \mathrm{s}$ \\
\hline 0 & 8 & $0.66 \pm 0.04$ & $22.1 \pm 0.9$ & $6.0 \pm 0.6$ & $216 \pm 28$ & $5.9 \pm 0.8$ \\
\hline 5 & 10 & $0.67 \pm 0.04$ & $22.3 \pm 0.7$ & $6.2 \pm 0.5$ & $208 \pm 22$ & $5.8 \pm 0.6$ \\
\hline 10 & 10 & $0.79 \pm 0.04$ & $23.9 \pm 1.0$ & $6.0 \pm 0.4$ & $190 \pm 14$ & $5.2 \pm 0.5$ \\
\hline
\end{tabular}

All tubules were bathed in media containing $10 \mathrm{mM}$ total ammonia $\left(\mathrm{tNH}_{3}\right)$.

that luminal $\mathrm{K}^{+}$does not affect the efflux of total ammonia out of the tubular lumen and suggest that the luminal $\mathrm{K}^{+}$affects net secretion of total ammonia by enhancing secretion into the luminal fluid.

In another experiment we examined the effect of luminal $\mathrm{K}^{+}$concentration on the transepithelial flux of total ammonia from the peritubular (bath) solution to the luminal fluid (Table III). This was accomplished by adding $10 \mathrm{mM}$ ammonia to the bath solution and measuring the total ammonia leaving the distal end of the perfused proximal tubule segment under conditions in which the perfusion solution contained different $\mathrm{K}^{+}$ concentrations $(0,5$, or $10 \mathrm{mM})$ while maintaining a constant bath $\mathrm{K}^{+}$concentration of $5 \mathrm{mM}$. The net luminal ammonia influx rates and calculated apparent total ammonia permeabilities did not significantly differ among the three groups of proximal tubule segments perfused with 0,5 , or $10 \mathrm{mM} \mathrm{K}^{+}$ solutions. Thus, altering the intraluminal $\mathrm{K}^{+}$concentration had no significant effect on transepithelial bath-to-lumen ammonia entry.

\section{Discussion}

The results of the present study demonstrate the effects of altered bath and luminal potassium concentrations on total ammonia production and net luminal total ammonia secretion by mouse proximal tubule segments perfused in vitro. The effects of altered ambient potassium concentration were acute and independent of extrarenal hormonal influences.

The total ammonia production and net luminal secretion rates obtained under control conditions, i.e., $5 \mathrm{mM}$ potassium concentration in bath and perfusate, were similar to those observed by us previously in the same segment of the mouse proximal tubule. The effect of high potassium concentrations in the bath and perfusate on total ammonia production was similar to the effect of high ambient potassium concentrations on total ammonia production rates in rat kidney tissue. Sastrasinh and Tannen demonstrated a $33-44 \%$ suppression of ammonia production in isolated perfused whole rat kidneys in which the potassium concentration was increased from 5 to 9 $\mathrm{mM}$ or from 4.6 to $8.0 \mathrm{mM}$, and a $12 \%$ fall in ammonia production rates in isolated cortical tubules in which the potassium concentration was increased from 5 to $9 \mathrm{mM}$ (7). Sleeper and colleagues also demonstrated the suppression of ammonia production from L-glutamine by high ambient potassium concentrations, but much higher concentrations of potassium (25 $\mathrm{mM}$ ) were required to demonstrate a significant inhibition of ammonia production from L-glutamine in rat cortical slices 
(6). Our data are qualitatively similar to those obtained in other preparations in that they demonstrate significantly lower rates of total ammonia production in proximal tubule segments bathed and perfused with $8 \mathrm{mM}$ potassium KRB buffer than in segments bathed and perfused in $5 \mathrm{mM}$ whether L-glutamine was present in or absent from the luminal perfusate.

On the other hand, these data indicate that when L-glutamine was present in the bath only, tubules perfused and bathed with buffer containing $2 \mathrm{mM}$ potassium produced total ammonia at higher rates than tubules perfused and bathed with control KRB buffer. These data were qualitatively and quantitatively different from observations by others on the effects of altered ambient potassium concentration on total ammonia production rates. Sastrasinh and Tannen showed an inhibitory effect of low potassium concentration on total ammonia production by a cortical tubule preparation (7), and Sleeper and colleagues demonstrated a $10 \%$ stimulation of total ammonia production in renal cortical tissue slices with reduction of ambient potassium concentration to $0 \mathrm{mM}(6)$. Thus, our data demonstrated stimulation of total ammonia production with a lesser degree of reduction in potassium concentration than has been observed previously in vitro.

The quantitative and qualitative differences in the results of the present study and those of others may be related to species differences or to differences in preparations. One of the differences between previous studies and our studies was that the luminal aspect of the proximal tubules in the present study was not exposed to L-glutamine, while in cortical tubules or isolated perfused whole kidney preparations the luminal aspect of the proximal tubules was exposed to the substrate in the incubation medium or in the perfusion solution. In the present studies we omitted L-glutamine from the luminal perfusion solution because L-glutamine is absorbed in the earliest subsegments of the proximal convoluted tubule and its delivery to later proximal convoluted tubule segments such as the $\mathrm{S}_{2}$ segment may be minimal (13). Thus the physiological luminal concentration of L-glutamine depends on the distance from the glomerulus so that the use of luminal perfusion solutions that do not contain L-glutamine may more closely correspond to in vivo conditions in the more distal portions of the proximal tubule. Addition of L-glutamine to the perfusion solution as well as to the bath increased total ammonia production rates under control conditions with $5 \mathrm{mM} \mathrm{K}^{+} \mathrm{KRB}$ buffer, and eliminated the stimulatory effect of the reduction of ambient potassium concentration on total ammonia production. In contrast, addition of L-glutamine to the perfusion solution did not eliminate the inhibitory effect of high $(8 \mathrm{mM})$ potassium concentration on total ammonia production. The latter finding is consistent with the results obtained with other in vitro preparations showing inhibition of total ammonia production in response to high potassium concentrations. Thus, the inhibitory effect of high potassium concentration on total ammonia production may be observed in proximal tubule segments exposed to luminal as well as peritubular L-glutamine, while the stimulatory effect of low potassium concentration may be limited to proximal tubule segments exposed to minimal luminal concentrations of L-glutamine and may not occur in the early portions of the proximal tubule in which luminal L-glutamine delivery may be important.

Why low bath potassium concentration stimulates ammonia production in the absence of luminal L-glutamine but has no effect in the presence of luminal L-glutamine is not clear. Low bath potassium concentration may stimulate ammonia production by enhancing basolateral uptake of L-glutamine or by increasing ammonia generation from L-glutamine when L-glutamine is present only in the bath (basolateral) solution. The results of the present study demonstrate substantial rates of L-glutamine reabsorption and suggest high rates of delivery to the cell. Thus, the addition of L-glutamine to the luminal perfusate, by providing a surplus of substrate, may alter an effect of low $\mathrm{K}^{+}$concentration to stimulate metabolism of glutamine to ammonia or to enhance basolateral uptake of glutamine.

One of the advantages of the in vitro microperfusion technique is that luminal conditions may be altered while maintaining constant bath conditions. Our results demonstrate that there is no significant effect of altering the luminal potassium concentration and indicate that changes in concentration of potassium at the luminal membrane do not regulate total ammonia production rates. This lack of effect of altered luminal potassium concentration on total ammonia production is similar to the lack of effect of lowered intraluminal $\mathrm{pH}$ on total ammonia production (9). Thus, peritubular rather than intraluminal potassium concentration is important in the regulation of total ammonia production by the proximal tubule.

The hydrated radius of ammonium ion is similar to that of potassium ion, suggesting that potassium and ammonium ions might compete for or share transport mechanisms. In fact, ammonium ions may be transported instead of potassium ion on the $\mathrm{Na}^{+}-\mathrm{K}^{+}$ATPase of the proximal tubule $(14,15)$, and probably on the $\mathrm{NaKCl}$ cotransporter in the thick ascending limb of Henle (16). The present studies in isolated mouse proximal tubules demonstrate the influence of ambient $\mathrm{K}^{+}$ concentration on net luminal secretion of ammonia. When bath and luminal $\mathrm{K}^{+}$concentration was lowered from 5 to 2 $\mathrm{mM}$, the rate of total ammonia production was higher but net luminal secretion of total ammonia was lower. In proximal tubule segments bathed in and perfused with higher potassium concentrations $(8 \mathrm{mM})$, the total ammonia production rate was lower but the net total ammonia secretion rate was not different from the corresponding rate observed in tubules bathed in and perfused with control KRB buffer $\left(5 \mathrm{mM} \mathrm{K}^{+}\right)$. Furthermore, our experiments examining the effect of intraluminal $\mathrm{K}^{+}$concentration on net ammonia secretion at a constant bath $\mathrm{K}^{+}$concentration demonstrated that higher intraluminal $\mathrm{K}^{+}$concentrations are associated with higher rates of net luminal secretion of ammonia, while total ammonia production rates remain constant.

In our previous study we demonstrated the important role of $\mathrm{Na}^{+}-\mathrm{H}^{+}$exchange on net luminal secretion of total ammonia and suggested that the $\mathrm{Na}^{+}-\mathrm{H}^{+}$exchanger facilitated net total ammonia secretion by operating as an $\mathrm{Na}^{+}-\mathrm{NH}_{4}^{+}$exchanger (10). To assess the role of the $\mathrm{Na}^{+}-\mathrm{H}^{+}$exchanger in the effect of high luminal potassium concentration on net total ammonia secretion, we inhibited $\mathrm{Na}^{+}-\mathrm{H}^{+}$exchange activity by perfusing proximal tubule segments with perfusion solutions consisting of a modified KRB buffer containing $0.1 \mathrm{mM}$ amiloride and 5 or $10 \mathrm{mM}$ potassium. Inhibition of $\mathrm{Na}^{+}-\mathrm{H}^{+}$exchange had little effect on the stimulation of net luminal total ammonia secretion in that the absolute differences in the rate of net luminal secretion of total ammonia observed in tubules perfused with 5- and $10-\mathrm{mM} \mathrm{K}^{+}$solutions were similar 
whether the perfusate consisted of the standard KRB buffer without amiloride (Fig. 5) or the modified KRB buffer containing amiloride (Fig. 6). Changes in luminal potassium did not significantly affect collected luminal fluid $\mathrm{pH}$, indicating that $\mathrm{pH}$ gradients that would alter diffusion of nonionic ammonia and trapping of ammonium ion were not generated by altered luminal potassium concentration. Thus, the mechanism for the effect of luminal potassium on net total ammonia secretion is not related to changes in total ammonia production rates or to changes in luminal fluid $\mathrm{pH}$.

Another mechanism by which net luminal secretion could be affected by luminal potassium concentration would be through an effect on ammonia efflux rate. An increase in the rate of total ammonia reabsorption would reduce net luminal secretion by increasing the efflux of total ammonia and decreasing the amount of total ammonia delivered in the luminal fluid to the distal end of the perfused segment. The present data demonstrate that total ammonia efflux occurs at a high rate and is not altered by varying the luminal potassium concentration. In addition, our study demonstrated that bath-tolumen transepithelial influx of total ammonia was not affected by intraluminal potassium concentration. Taken together, these results suggest that the effect of luminal potassium on net ammonia secretion is not due to altered efflux of total ammonia, does not result from changes in transepithelial driving forces, and may result from direct effects of luminal potassium concentration to alter cell-to-lumen transport of ammonia.

The high rates of total ammonia efflux and influx yielded estimates of total ammonia permeabilities of $\sim 6 \times 10^{-4} \mathrm{~cm} / \mathrm{s}$ (Tables II and III). Such values for total ammonia permeability are consistent with the estimated permeabilities for total ammonia observed by Simon et al. in the rat proximal tubule (17), but are an order of magnitude higher than the permeabilities observed by Garvin et al. in rabbit proximal tubule segments (18). Such differences may be related to differences in species.

Good has suggested that changes in luminal potassium concentration in the physiologic range may modulate ammonium transport in the thick ascending limb such that high luminal potassium concentrations inhibit ammonium ion reabsorption in this segment, thereby reducing the accumulation of total ammonia in the medulla (16). In the present study, high luminal potassium concentrations in proximal tubule segments stimulated net secretion of total ammonia into the lumen. In vivo peritubular and intraluminal potassium concentrations do not differ greatly in the proximal tubule, so that under physiologic conditions the apical and basolateral aspects of the proximal tubule are exposed to the similar potassium concentrations. The effects of luminal potassium concentration on net luminal secretion of total ammonia seem to counterbalance the effects of basolateral and luminal potassium to alter production. Indeed, our data indicate that with high bath and luminal potassium concentrations, net luminal secretion is unchanged compared with control tubules bathed and perfused in $5 \mathrm{mM}$ potassium buffer even though total ammonia production rates were lower. With low bath and luminal potassium concentrations, net luminal secretion is lower than values observed in control tubules even though total ammonia production rates were higher. Therefore, the overall influence of potassium on the net secretion of total ammonia by the proximal tubule may reflect the contrasting effects of potassium on production and secretion in this segment.

Although clinical disorders associated with hyperkalemia (19) or hypokalemia (20) may be associated with altered rates of potassium excretion, they generally reflect more chronic changes in plasma potassium concentration and total potassium balance. The results of the present studies clearly demonstrate that acute elevation in ambient potassium concentration to levels that may occur in vivo suppresses total ammonia production rates in the proximal tubule perfused in vitro in the presence or absence of glutamine in the luminal perfusion solution, while an acute reduction of the ambient potassium concentration stimulates total ammonia production rates in the absence of luminal L-glutamine.

In conclusion, ambient potassium concentration has acute and direct effects on total ammonia production and net secretion of total ammonia in the mouse proximal tubule perfused in vitro. High bath and luminal potassium concentrations, but not high luminal potassium concentration alone, inhibit total ammonia production rates, while low bath and luminal potassium concentrations, but not low luminal potassium concentration alone, stimulate total ammonia production rates. The stimulation of ammonia production by low bath potassium is not observed when L-glutamine is present in both bath and luminal solutions. On the other hand, high luminal potassium concentration stimulates, while low luminal potassium concentration inhibits, net luminal secretion of total ammonia in a way that is not related to changes in rates of total ammonia production, is independent of $\mathrm{Na}^{+}-\mathrm{H}^{+}$exchange activity, and is not due to changes in transepithelial fluxes of total ammonia in the isolated perfused proximal tubule.

\section{Acknowledgments}

The author thanks Dr. George Sachs for his encouragement during these studies.

This work was supported by the Veterans Administration, by the National Institute of Diabetes and Digestive and Kidney Diseases (DK-38463), and by a Grant-in-Aid from the American Heart Association. Dr. Nagami is a Clinical Investigator of the Veterans Administration.

\section{References}

1. Tannen, R. L. 1977. Relationship of renal ammonia production and potassium homeostasis. Kidney Int. 11:453-465.

2. Tannen, R. L. 1970. The effect of uncomplicated potassium depletion on urinary acidification. J. Clin. Invest. 49:813-827.

3. Pagliara, A. S., and A. D. Goodman. 1970. Relation of renal cortical gluconeogenesis, glutamate content and production of ammonia. J. Clin. Invest. 49:1967-1974.

4. Kamm, D. E., and G. L. Strope. 1973. Glutamine and glutamate metabolism in renal cortex from potassium-depleted rats. Am. J. Physiol. 224:1241-1248.

5. Tannen, R. L., E. Wedell, and R. Moore. 1973. Renal adaptation to a high potassium intake. The role of hydrogen ion. J. Clin. Invest. 52:2089-2101.

6. Sleeper, R. S., P. Belanger, G. Lemieux, and H. G. Preuss. 1982. Effects of in vitro potassium on ammoniagenesis in rat and canine kidney tissue. Kidney Int. 21:345-353.

7. Sastrasinh, S., and R. L. Tannen. 1983. Effects of potassium on renal $\mathrm{NH}_{3}$ production. Am. J. Physiol. 244:F383-F391.

8. Nagami, G. T., and K. Kurokawa. 1985. Regulation of ammonia 
production by mouse proximal tubules perfused in vitro. Effect of luminal perfusion. J. Clin. Invest. 75:844-849.

9. Nagami, G. T., C. M. Sonu, and K. Kurokawa. 1986. Ammonia production by isolated mouse proximal tubules perfused in vitro. Effect of metabolic acidosis. J. Clin. Invest. 78:124-129.

10. Nagami, G. T. 1988. Luminal secretion of ammonia in the mouse proximal tubule perfused in vitro. J. Clin. Invest. 81:159-164.

11. Pishak, M. R., and A. T. Phillips. 1979. A modified radioisotopic assay for measuring glutamine synthetase activity in tissue extracts. Anal. Biochem. 94:82-88.

12. Scheffe, H. 1959. The Analysis of Variance. John Wiley \& Sons, New York. 477 pp.

13. Silbernagl, S. 1980. Tubular reabsorption of L-glutamine studied by free-flow micropuncture and microperfusion of rat kidney. Int. J. Biochem. 12:9-16.

14. Garvin, J. L., M. B. Burg, and M. A. Knepper. 1985. Ammonium replaces potassium in supporting sodium transport by the $\mathrm{Na}^{+}-\mathrm{K}^{+}$ATPase of renal proximal straight tubules. Am. J. Physiol. 249:F785-F788.
15. Kurtz, I., and R. S. Balaban. 1986. Ammonium as a substrate for $\mathrm{Na}^{+}-\mathrm{K}^{+}$-ATPase in rabbit proximal tubules. Am. J. Physiol. 250:F497-F502.

16. Good, D. W. 1987. Effects of potassium concentration on ammonium transport by medullary thick ascending limb. J. Clin. Invest. 80:1358-1365.

17. Simon, E. E., B. Fry, K. Hering-Smith, and L. L. Hamm. 1988. Ammonia loss from rat proximal tubule in vivo: effects of luminal $\mathrm{pH}$ and flow rate. Am. J. Physiol. 255:F861-F867.

18. Garvin, J. L., M. B. Burg, and M. A. Knepper. 1987. $\mathrm{NH}_{3}$ and $\mathrm{NH}_{4}{ }^{+}$transport by rabbit renal proximal straight tubules. Am. J. Physiol. 252:F232-F239.

19. Szylman, P., O. S. Better, C. Chaimowitz, and A. Rosler. 1976. Role of hyperkalemia in the metabolic acidosis of isolated hypoaldosteronism. N. Engl. J. Med. 294:361-365.

20. Baertl, J. M., S. M. Sancetta, and G. H. Gabuzda. 1963. Relation of acute potassium depletion on renal ammonium metabolism in patients with cirrhosis. J. Clin. Invest. 42:696-706. 